\title{
Removal of methylene blue using lemon grass ash as an adsorbent
}

\author{
Harminder Singh` and Dawa Tshering B \\ Department of Chemistry, Lovely Professional University, Punjab 144402, India
}

\section{Article Info}

Received 11 December 2013

Accepted 26 March 2014

*Corresponding Author

E-mail: harminder_env@yahoo.com

\section{Open Access}

DOI: http://dx.doi.org/

10.5714/CL.2014.15.2.105

This is an Open Access article distributed under the terms of the Creative Commons Attribution Non-Commercial License (http://creativecommons.org/licenses/ by-nc/3.0/) which permits unrestricted non-commercial use, distribution, and reproduction in any medium, provided the original work is properly cited.

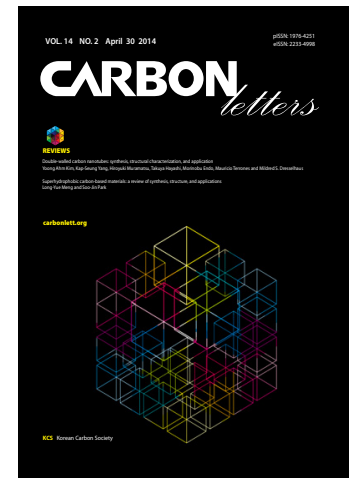

http://carbonlett.org

pISSN: $1976-4251$

elSSN: 2233-4998

Copyright $\odot$ Korean Carbon Society

\begin{abstract}
Wastewater from textile industries is a major cause of water pollution in most developing countries. In order to address the issues of water pollution and high cost for treatment processes, the use of an inexpensive and environmentally benign adsorbents has been studied. The objective was to find a better alternative to the conventional methods. Lemon grass waste (ash) collected from a lemon grass stream distillation subunit in Bhutan was tested for dye removal from aqueous solutions. The study investigated the removal of methylene blue using the following operational parameters: initial concentration $(100-600 \mathrm{mg} / \mathrm{L})$, contact time, adsorbent dose $(0.1-0.55 \mathrm{gm} / 100 \mathrm{~mL})$, and $\mathrm{pH}(3-10)$. It was found that the percentage removal of dye increased with a decrease of the initial concentration and increased contact time and dose of adsorbent. The basic $\mathrm{pH}$ solution of dye showed better adsorption capacity as compared to the acidic dye solution. Langmuir and Freundlich adsorption isotherms were fitted to the data well. Data fitted better to Lagergren pseudo 2nd order kinetics than a 1st order kinetic model. Surface morphology was also examined via scanning electron microscopy. An elemental analysis was also carried out and the chemical composition and functional groups were analyzed using energy dispersive X-ray spectroscopy and Fourier transform infrared spectroscopy techniques, respectively. The obtained results indicate that lemon grass ash could be employed as a low cost alternative to commercial activated carbon in wastewater treatment for the removal of dyes.
\end{abstract}

Key words: adsorption, methylene blue, low cost adsorbent, scanning electron microscopy, infrared spectroscopy

\section{Introduction}

Advanced technologies have played a greater role in the progress of business firms in enhancing their profitability, but much less attention has been paid to addressing environmental concerns. Environmental pollution is one of the greatest concerns of the 21 st century. Among the many environmental issues, water pollution is of great concern since water is the prime necessity of life and extremely vital for the survival of all living organisms. Despite various awareness programs and campaigns, water pollution is on the rise owing to continually increasing amounts of industrial wastage and waste from domestic sewage.

The textile industry uses huge quantities of water in all processing operations. Almost all dyes, specialty chemicals, and finishing chemicals are applied to textiles in water baths. Most of the fabric preparation steps, including desizing, scouring, bleaching, and mercerizing, use water. Furthermore, each of these steps involves thorough washing of the fabric to remove all chemicals used [1]. The water used in the processing is usually returned to the environment without proper treatment. The textile industry releases huge amounts of colored effluent daily. Wastewater released by these industries pollutes the fresh water of streams, ponds, and rivers, as well as underground water bodies. Dyes are used widely in many industries such as textile production, dyestuff manufacturing, leather tanning, food 
preparation, paper production, and printing in order to give color to their products.

Every year tons of dyes are produced worldwide and significant amounts of the total production are lost in wastewater during synthesis and processing. This release of high colored effluents into natural water has become a serious environmental problem. Specifically, highly colored effluents into natural water bodies obstruct light penetration, disturbing biological processes within them [2]. In addition, many dyes are toxic to various organisms, causing direct damage to aquatic species in particular. Some dyes can cause allergic dermatitis, skin irritation, cancer, and mutation in humans also $[2,3]$. Dealing with these types of pollution is therefore very important, especially in developing countries.

Adsorption is one of the effective methods for the removal of dyes from waste effluent. The process of adsorption is advantageous over other methods because it is sludge-free, offers clean operation, and the dyes are completely removed, even from diluted solutions. Activated carbon (powdered or granular) is the most widely used adsorbent because it has excellent adsorption efficiency for organic compounds. However, commercially available activated carbons are expensive. This has recently prompted many studies on production of low cost alternatives adsorbents. A number of agricultural waste types and byproducts of cellulosic source have been studied for their capacity to remove dyes from aqueous solutions. Soil nano-clays [1], bagasse (waste material from sugar cane) [2], waste wood pallets [4], raw bagasse, and tartaric acid-modified bagasse [5], tamarind fruit shell [6], rice husk, cotton, bark, hair and coal [7], raw pummelo peel [8], ghassoul, natural clay [9], Ricinus communis epicarp activated carbon [10], activated carbon prepared from rice husk [11], roots of Tephrosia purpurea, leaves and stems of Terminalia arjuna and bivalve snail shells [12], teak tree (Tectona grandis) bark powder [3], orange peel, neem leaves, banana peel, [13], water hyacinth root plant [14], miswak leaves [15], fly ash [16], orange and banana peel [17], ground nut shell powder [18], and mustard waste ash and buffalo dung ash [19] have been reported in the literature as low cost adsorbents for methylene blue. In the present study, lemon grass waste ash (LGA) was evaluated for the removal of methylene blue from an aqueous solution. Lemon grass is used in oil distillation units for the extraction of useful lemongrass oil. Lemon grass becomes waste after the extraction of oil and it is freely available as waste. Therefore, this study explores this waste as an economical adsorbent for the removal of dyes. Activated carbons are prepared by various methods such as carbonization, activation by steam, and activation by the use of chemical agents, which add to the production cost. On the other hand, natural biowaste materials such as lemon grass do not require these treatments and therefore are more economical than activated carbons and other synthetic adsorbents.

\section{Experimental}

\subsection{Preparation of adsorbent}

In the present study the adsorbent used was LGA. Lemon grass waste was collected from a lemongrass oil distilled subunit in Trashi Gang, Bhutan. The adsorbent was washed thoroughly with normal water and with distilled water to remove dust and other impurities. The washed adsorbent was dried in a hot air oven at $60^{\circ} \mathrm{C}$ to remove the moisture content. The dried lemon grass waste was made from ash in a muffle furnace at $500^{\circ} \mathrm{C}$ for $2 \mathrm{~h}$ and was stored in an air tight plastic container for further use. The adsorbent was sieved through an I.S.70 mesh screen $(70 \mu \mathrm{m})$ prior to its use.

\subsection{Adsorbent Surface Characterization}

The characteristics of the adsorbents were examined using a scanning electron microscopic (SEM) analysis, energy dispersive X-ray spectroscopy (EDX), and Fourier transform infra-red (FT-IR) spectroscopy. In order to obtain a clear picture of the particle size and the external surface of the material images of the adsorbent were taken with a SEM (model: ZEISS EVO-40 series SEM: Carl Zeiss SMT Ltd., Cambridge, England) at different magnifications. The images were taken for a pure adsorbent as well as after interaction with the dye. The chemical compositions were analyzed by EDX. For this EDX with an X-Flash Silicon Drift Detector-4010, $10 \mathrm{~mm}^{2}$, type 1106 Bruker AXS, Germany was used. FT-IR spectra of LGA were obtained using a Fourier transform infrared spectrophotometer (Shimadzu-8400s) to elucidate the functional groups present in LGA. For measuring IR spectra, the powdered LGA was encapsulated in a $\mathrm{KBr}$ pellet and spectra were obtained in a range of 400 to $4000 \mathrm{~cm}^{-1}$.

\subsection{Adsorption studies}

Stock solutions of methylene blue and crystal violet were prepared by dissolving $1 \mathrm{~g}$ of the respective dye in $1 \mathrm{~L}$ of the double distilled water $(1000 \mathrm{mg} / \mathrm{L})$. The solutions were used to make desired concentrations using double distilled water. The $\mathrm{pH}$ adjustments were made using hydrochloric acid and sodium hydroxide.

Batch mode experimental studies were carried out with a known weight of the adsorbent in $50 \mathrm{~mL}$ of working solution of different concentrations $(100-600 \mathrm{mg} / \mathrm{L})$ in a 100 $\mathrm{mL}$ conical flask with a stopper. These flasks were kept in a thermostatic shaker maintained at a temperature of $25^{\circ} \mathrm{C}$ and $150 \pm 10 \mathrm{rpm}$ for sufficient time to achieve equilibrium. After equilibration, the adsorbent was separated by centrifugation at $1800 \pm 100 \mathrm{rpm}$ for $10 \mathrm{~min}$ and the aqueous phase concentration of the dyes was analyzed using a UV-VIS spectrophotometer (Shimadzu-1800) by observing optical density at $662 \mathrm{~nm}$. This process was repeated to determine the effects of different adsorption parameters such as adsorbent dose (0.1-0.55 g/50 mL), $\mathrm{pH}(3-10)$, an contact time by keeping all other parameters at fixed values.

\subsection{Adsorption isotherms}

Adsorption isotherms can be use to determine the feasibility of using an adsorbent for a particular application. They are described by a plot between the amount of adsorbate adsorbed per unit weight of adsorbent $\left(\mathrm{Q}_{\mathrm{e}}\right)$ versus the equilibrium concentration of the adsorbate $\left(\mathrm{C}_{\mathrm{e}}\right)$.

The sorption equilibrium $\left(Q_{e}\right)$ uptake capacity in $\mathrm{mg} / \mathrm{g}$ for each sample is calculated according to mass balance and is expressed as

$$
\mathrm{Q}_{\mathrm{e}}=\left(\frac{\mathrm{C}_{\mathrm{o}}-\mathrm{C}_{\mathrm{e}}}{\mathrm{m}}\right) \mathrm{V}
$$

where $C_{o}$ and $C_{e}$ are the initial and equilibrium concentrations 
of dyes, respectively, $\mathrm{m}$ is the mass of adsorbent, and $\mathrm{V}$ is the volume of solution in liters [20].

Langmuir and Freundlich isotherms are the most frequently used isotherms. Langmuir isotherms describe the adsorption of adsorbate onto the surface of the adsorbent with the following assumptions [19]:

1) The surface of the adsorbent is in contact with a solution containing an adsorbate that is strongly attracted to the surface.

2) The surface has a specific number of sites where the solute molecules can be adsorbed.

3) The adsorption involves the attachment of only one layer of molecules to the surface, i. e. monolayer adsorption.

The linear form of the Langmuir model is represented as follows:

$$
\frac{1}{\mathrm{Qe}}=\frac{1}{\mathrm{Q}}+\frac{1}{\mathrm{bQCe}}
$$

The constant Q signifies the adsorption capacity $(\mathrm{mg} / \mathrm{g})$ and $b$ is the energy of adsorption $(\mathrm{L} / \mathrm{gm})$. The plot of $1 / \mathrm{Q}_{\mathrm{c}}$ verses $1 / C_{e}$ gives a straight line of the slope $1 / b Q$ and intercepts $1 / \mathrm{Q}$.

Langmuir adsorption is also expressed in terms of a dimensionless separation factor $R_{L}[21]$ and is defined as

$$
\mathrm{R}_{\mathrm{L}}=\frac{1}{1+\mathrm{bC}_{\mathrm{o}}}
$$

where $\mathrm{C}_{\mathrm{o}}$ is the highest initial dye concentration $(\mathrm{mg} / \mathrm{L})$ and $\mathrm{b}$ is the Langmuir constant. The parameter $\mathrm{R}_{\mathrm{L}}$ indicates the isotherm shape according to the adsorption characteristics:

$\mathrm{R}_{\mathrm{L}}>1$, the process is unfavorable

$\mathrm{R}_{\mathrm{L}}=1$, the process corresponds to linear relationship

$0<\mathrm{R}_{\mathrm{L}}>1$, the process is favorable

$\mathrm{R}_{\mathrm{L}}=0$, an irreversible process

The Freundlich adsorption isotherm is an adsorption isotherm, which is a curve relating the concentration of a solute on the surface of an adsorbent to the concentration of the solute in the liquid with which it is in contact [19]. The Freundlich adsorption isotherm in linear form is expressed as:

$$
\log Q_{e}=\log K_{F}+\frac{1}{n} \log C e
$$

where $\mathrm{K}_{\mathrm{F}}$ is an indicator of adsorption capacity: the higher the maximum capacity, the higher the $\mathrm{K}_{\mathrm{F}}$.

$1 / \mathrm{n}$ is a measure of intensity of adsorption. A higher $1 / \mathrm{n}$ value indicates more favorable adsorption.

$$
\text { Generally, } n<1 \frac{1}{n}>1
$$

\subsection{Sorption kinetics}

The linear forms of Lagergren pseudo-first order and pseudosecond order adsorption kinetic models were tested with the data obtained in the study for the effect of variation in contact time.

The linearized form of the pseudo-first order Lagergren equation can be presented as

$$
\log \left(Q_{e}-Q_{t}\right)=\log Q_{e}-\frac{k_{1, \text { ads }}}{2.303} \mathrm{t}
$$

and the linearized form of the pseudo-second order Lagergren equation is expressed as

$$
\frac{1}{\mathrm{Q}_{\mathrm{t}}}=\frac{1}{\mathrm{~h}}+\frac{1}{\mathrm{Q}_{\mathrm{e}}} \mathrm{t}
$$

where $\mathrm{Q}_{\mathrm{e}}$ is the mass of dye adsorbed at equilibrium $(\mathrm{mg} / \mathrm{g}), \mathrm{Q}_{\mathrm{t}}$ is the mass of dye adsorbed at time $\mathrm{t}(\mathrm{mg} / \mathrm{g}), \mathrm{k}_{1, \mathrm{ads}}$ is the pseudo first-order reaction rate of adsorption (per minute), $h$ is $k_{2} Q_{e}{ }^{2}$, and $\mathrm{k}_{2}$ is the pseudo-second-order rate constant of adsorption $\mathrm{mg} / \mathrm{g} / \mathrm{min}[22]$.

\section{Results and Discussion}

\subsection{Characterization of adsorbents}

3.1.1. FT-IR

FT-IR spectra are shown in Fig. 1. The absorption peak at 3429.56 corresponds to $-\mathrm{OH}$ stretching vibrations, the peaks at $1612.54 \mathrm{~cm}^{-1}$ and $1381.08 \mathrm{~cm}^{-1}$ correspond to $\mathrm{C}=\mathrm{C}$ stretching and $\mathrm{CH}_{3}$ bending vibration, and the peak at 1103.32 is $\mathrm{C}-\mathrm{O}$ stretching vibrations, respectively. As methylene blue is a cationic dye, the $-\mathrm{OH}$ functional group on the surface of LGA may increase the interaction between the adsorbent and the adsorbate, which contributes to the adsorption of methylene blue.

\subsubsection{Surface characterization of adsorbent (LGA)}

Surface morphology of LGA was analyzed by SEM and is represented in Figs. 2a and b. Fig. 2a clearly indicates that before the reaction LGA has a fibrous irregular structure and is in a pellet form. The length of the fiber ranges from 37

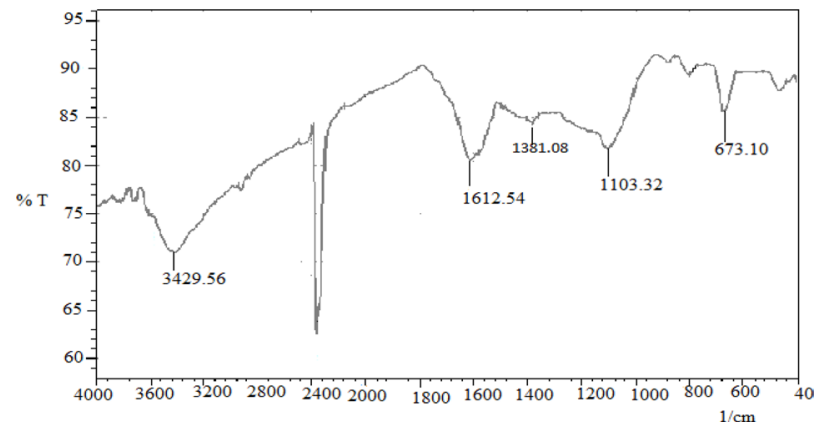

Fig. 1. Fourier transform infra-red spectroscopy of lemon grass waste ash.

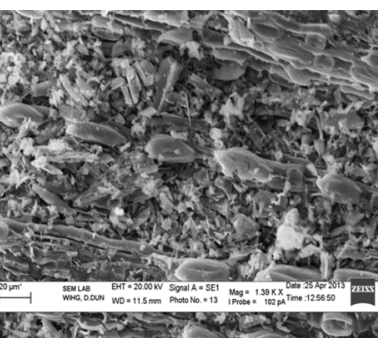

(a) Before reaction

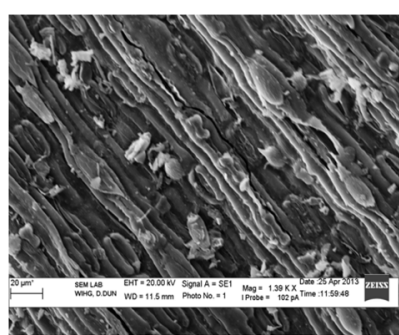

(b) After reaction
Fig. 2. Scanning electron microscopy image obtained before and after the reaction of the adsorbent at magnification of $1.39 \mathrm{KX}$. 
$\mu \mathrm{m}$ to $230 \mu \mathrm{m}$ and the width is $6.8 \mu \mathrm{m}$; the range of pellet size is between $4.9 \mu \mathrm{m}$ and $14.9 \mu \mathrm{m}$. Space between these fibers and pellets may serve as adsorption sites. These size ranges were analyzed on three different SEM images taken at various magnifications. After the reaction (Fig. 2b) the irregular structure was observed to be a regular fibrous structure, which indicates that the dye uniformly adsorbed on the surface of the adsorbent.

\subsubsection{EDX}

Elemental analyses of the adsorbent were carried out using EDX and the results are listed in Table 1. The oxygen content is high $(41.44 \%)$, which indicates that adsorption is favorable.

\subsection{Effect of contact time on adsorption}

The effect of initial dye concentration with contact time on the adsorption of methylene blue is represented in Fig. 4. The percentage removal is rapid in the first 10 to $20 \mathrm{~min}$ and then becomes slow. Percentage removal increased from $17.2 \%$ to $48.05 \%$ in $80 \mathrm{~min}$ and the amount of dye adsorbed per gram of adsorbent $\left(\mathrm{Q}_{\mathrm{e}}\right.$ in $\left.\mathrm{mg} / \mathrm{g}\right)$ also increased, from 103.78 to 288.302 . After $80 \mathrm{~min}$, very little change in the equilibrium concentration was noted. This may be due to the availability of a greater number of vacant adsorption sites at the initia stage. For further batch studies, the equilibrium time was set to $90 \mathrm{~min}$.

\subsection{Analysis of effect of $\mathrm{pH}$ on adsorption}

The sorption of methylene blue onto the adsorbent surface is influenced by the surface charges on the adsorbent and the initial $\mathrm{pH}$ of the solution [23]. Fig. 5 shows that the uptake of dye increases consistently with an increase in $\mathrm{pH}$ of the dye solution. Percentage removal of dye was increased from $8.82 \%$ at $\mathrm{pH} 1$ to $56.72 \%$ at $\mathrm{pH} 10$. As the $\mathrm{pH}$ of the solution increases ( $\mathrm{pH} 4-10)$, the surface charge density decreases and the elec-

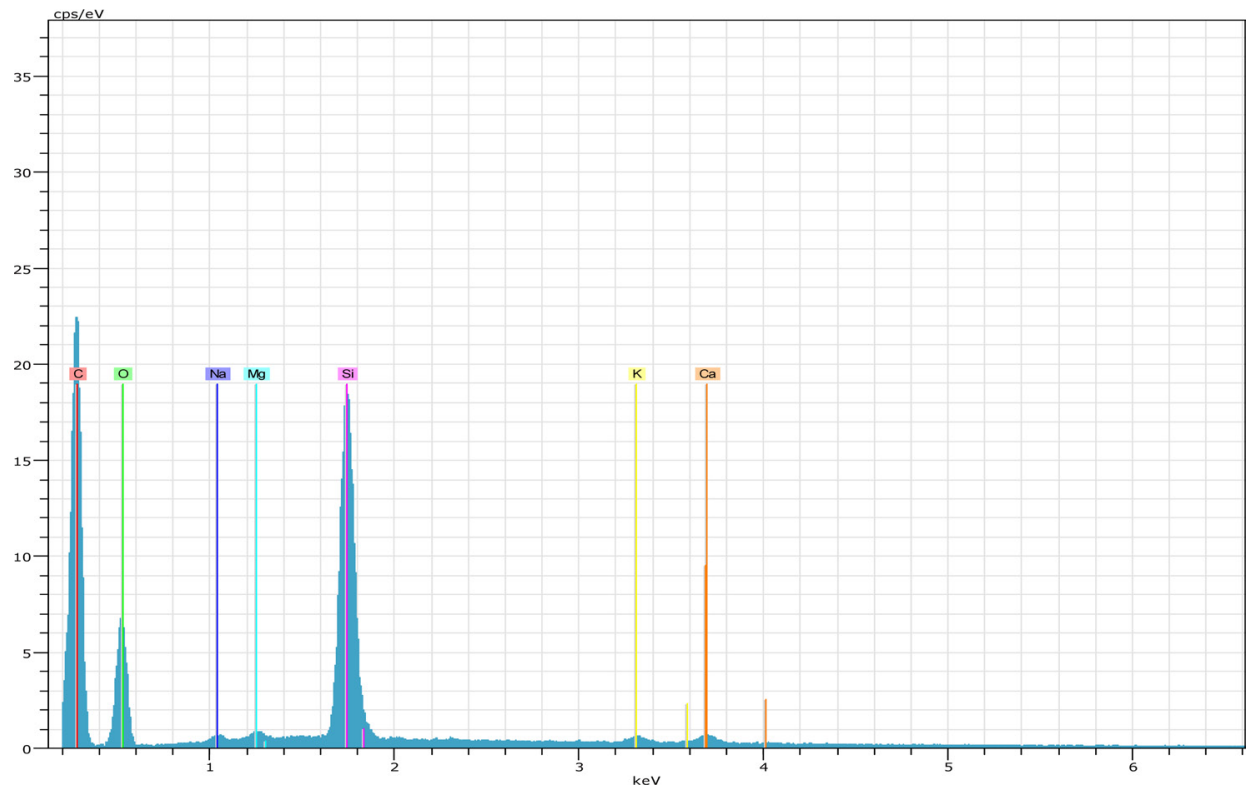

Fig. 3. Spectra obtained by energy dispersive X-ray spectroscopy of lemon grass waste ash.

\section{Table 1. Chemical composition obtained from energy dispersive $X$-ray spectroscopy analysis}

\begin{tabular}{cccccc} 
Elements & Series & Normalized composition (wt $\%)$ & Atomic composition (at\%) & Composition of oxides & Composition (wt\%) \\
\hline Sodium & K-series & 0.73 & 0.54 & $\mathrm{Na}_{2} \mathrm{O}$ & 3.46 \\
Magnesium & K-series & 0.72 & 0.50 & $\mathrm{MgO}$ & 4.20 \\
Silicon & K-series & 11.64 & 7.06 & $\mathrm{SiO}_{2}$ & 88.03 \\
Potassium & K-series & 0.40 & 0.17 & $\mathrm{~K} 2 \mathrm{O}$ & 1.70 \\
Calcium & K-series & 0.53 & 0.22 & $\mathrm{CaO}$ & 2.61 \\
Oxygen & K-series & 41.44 & 44.10 & $\mathrm{O}$ & $\mathrm{CO}_{2}$ \\
Carbon & K-series & 44.45 & 47.30 & & 00.00 \\
\hline
\end{tabular}




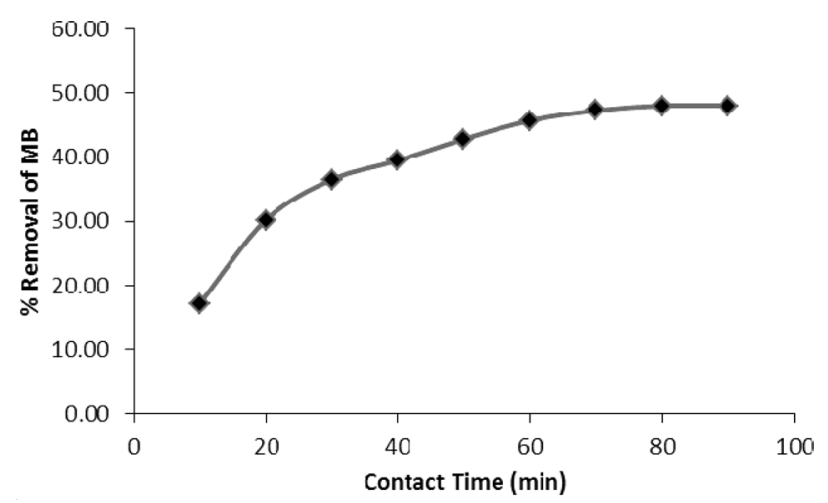

Fig. 4. Effect of contact time ( $\mathrm{min}$ ) between methylene blue and lemon grass waste ash (temperature $=25^{\circ} \mathrm{C}$, dose $=0.1 \mathrm{mg} / 100 \mathrm{~mL}, \mathrm{rpm}=150 \pm$ 10 , Conc. $=600 \mathrm{mg} / \mathrm{L}, \mathrm{pH}=7.8)$.

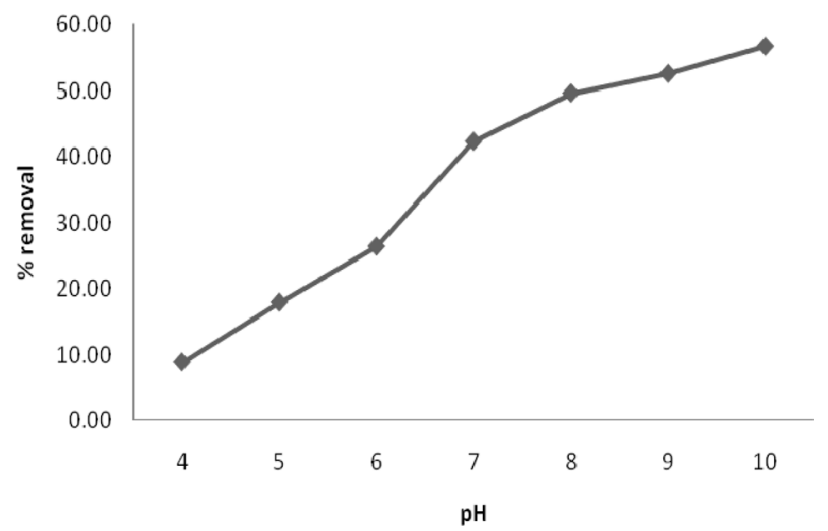

Fig. 5. Effect of initial $\mathrm{pH}$ of methylene blue solution (temperature $=$ $25^{\circ} \mathrm{C}$, dose $=0.1 \mathrm{mg} / 100 \mathrm{~mL}, \mathrm{rpm}=150 \pm 10$, Conc. $=600 \mathrm{mg} / \mathrm{L}$, equilibrium time $=90 \mathrm{~min}$ ).

trostatic repulsions between the adsorbent and the positively charged basic dyes also decrease, thereby increasing the extent of adsorption. Thus there exists an electrostatic attraction between the positively charged cationic methylene blue molecules and negatively charged surface of the adsorbent, which favors adsorption of the methylene blue [24]. Similar results have been reported elsewhere [19].

\subsection{Effect of adsorbent dose on initial con- centration}

The adsorption of methylene blue studied by varying the adsorbent dosage is represented in Fig. 6. The results indicate that there is an increase of the percentage removal $(31.7 \%$ at 0.05 $\mathrm{g} / 100 \mathrm{~mL}$ to 99.81 at $0.55 \mathrm{~g} / 100 \mathrm{~mL}$ ) with an increase of the adsorbent dose. This could be due to increased availability of surface active sites resulting from the increased dose and conglomeration of the adsorbent [21]. On the other hand, the value of $\mathrm{Q}_{\mathrm{e}}$ also decreased from 380 to $108.2 \mathrm{mg} / \mathrm{g}$ at 0.05 and 0.55 $\mathrm{g} / 100 \mathrm{~mL}$ respectively. The decrease in the amount of dye adsorbed per gram of the adsorbent $\left(\mathrm{Q}_{\mathrm{e}}\right)$ with an increase of the adsorbent dose is mainly due to unsaturation of adsorption sites through the adsorption process [25].

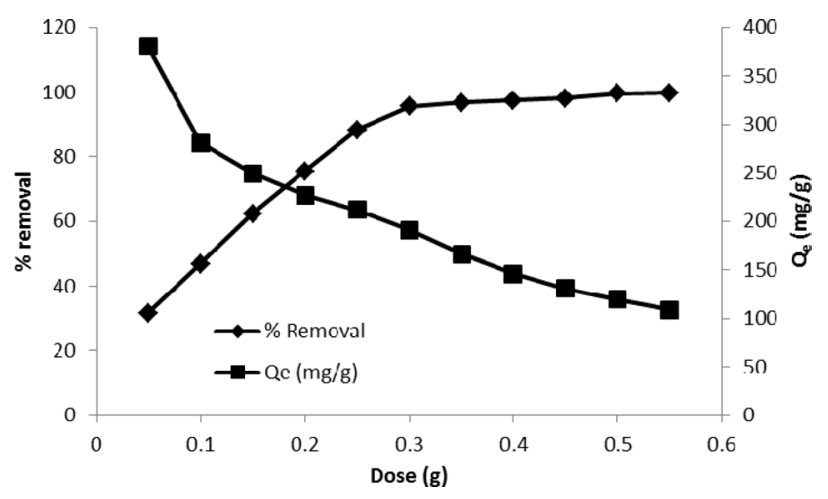

Fig. 6. Effect of adsorbent dose on the amount of dyes adsorbed per unit weight $\left(Q_{\mathrm{e}}\right)$ and $\%$ removal of dyes (temperature $=25^{\circ} \mathrm{C}$, rotations per minute $=150 \pm 10$, concentration of dyes $=600 \mathrm{mg} / \mathrm{L}$, equilibrium time $=$ $90 \mathrm{~min} \mathrm{pH}=7.8$.

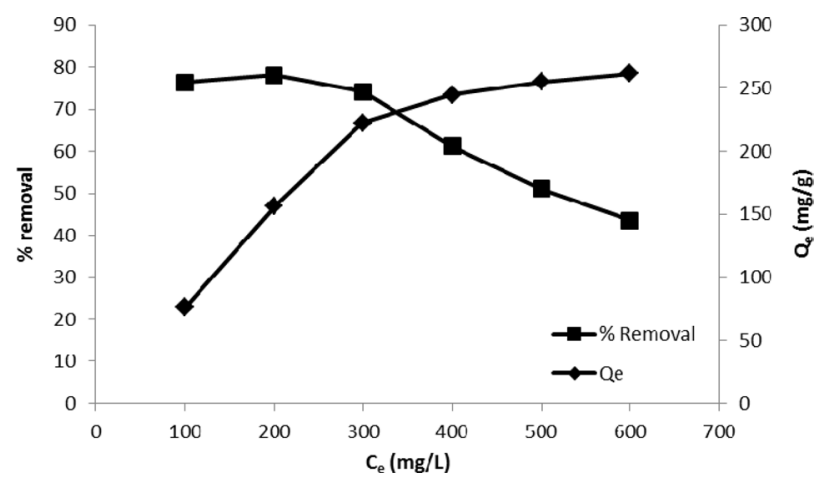

Fig. 7. Effect of initial dye concentration $\left(C_{0}\right)$ on the amount of dyes adsorbed per unit weight $\left(Q_{e}\right)$ and $\%$ removal of dyes (temperature $=25^{\circ} \mathrm{C}$ rotations per minute $=150 \pm 10$, adsorbent dose $=0.1 \mathrm{mg} / 10 \mathrm{~mL}$, equilibrium time $=90 \mathrm{~min}, \mathrm{pH}=7.8$ ).

\subsection{Effect of initial concentration of dye}

The effect of the initial concentration of the dye was observed by varying the initial dye concentration from 100 to $600 \mathrm{mg} / \mathrm{L}$ and keeping all other conditions constant. It was observed that the percentage removal decreased (76.4 to $43.6 \%$ ). This reveals that there is a reduction of immediate solute adsorption due to the lack of available active sites required for high initial concentration of the dye. Initially, dye molecules rapidly reach the boundary layer by mass transfer; they then slowly diffuse from the boundary layer onto the adsorbent because many of the available sites have been occupied, and they diffuse into the porous structure of the adsorbent. In contrast, the amount of dye adsorbed per gram of the adsorbent $\left(\mathrm{Q}_{\mathrm{e}}\right)$ increased (76.4 to $261.4 \mathrm{mg} / \mathrm{g}$ ) with an increase in the initial concentration of the dye. An increase in the initial concentration of the dye contributes to the driving force to overcome mass transfer resistance of ions between the adsorbent and bulk fluid phases, which in turn increases the uptake of dye molecules. Moreover, the number of collisions between dye molecules and the adsorbent also increases, resulting in an increase of the adsorption [19]. 


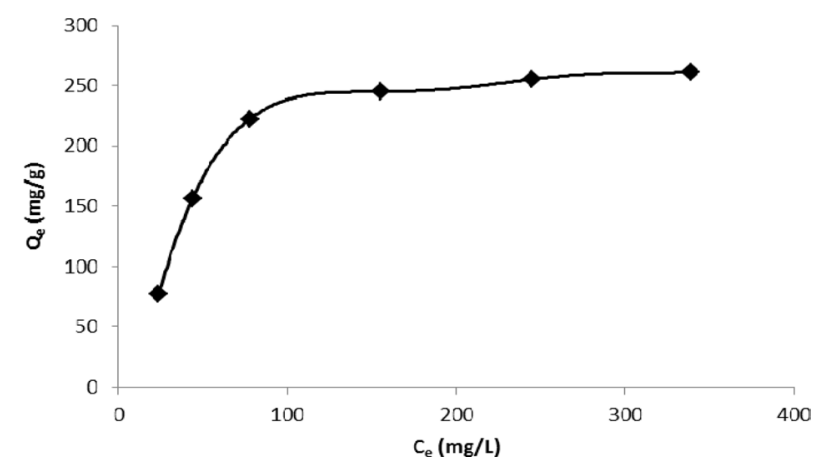

Fig. 8. Adsorption isotherm (temperature $=25^{\circ} \mathrm{C}$, dose $=0.1 \mathrm{~g} / 100 \mathrm{~mL}$, $r p m=150 \pm 10, \mathrm{pH} 7.8$, equilibrium time $=90 \mathrm{~min}$ ).

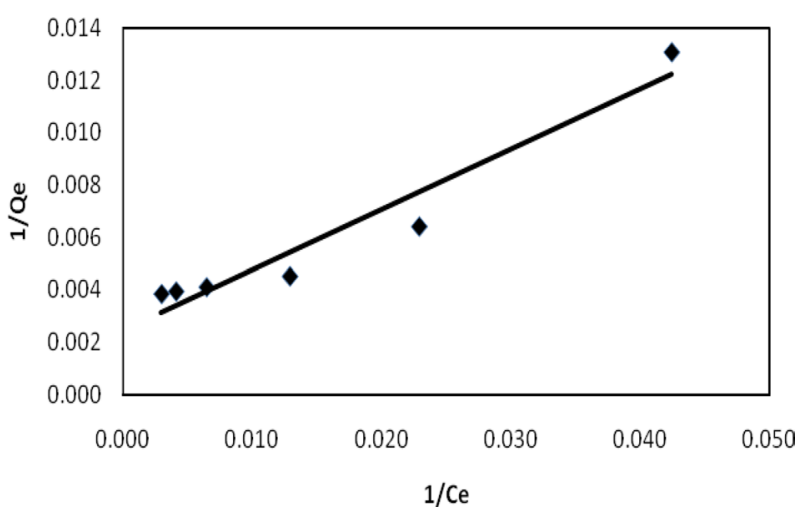

Fig. 9. Langmuir isotherm (temperature $=25^{\circ} \mathrm{C}$, dose $=0.1 \mathrm{~g} / 100 \mathrm{~mL}$, $\mathrm{rpm}=150 \pm 10, \mathrm{pH} 7.8$, equilibrium time $=90 \mathrm{~min}$ ).

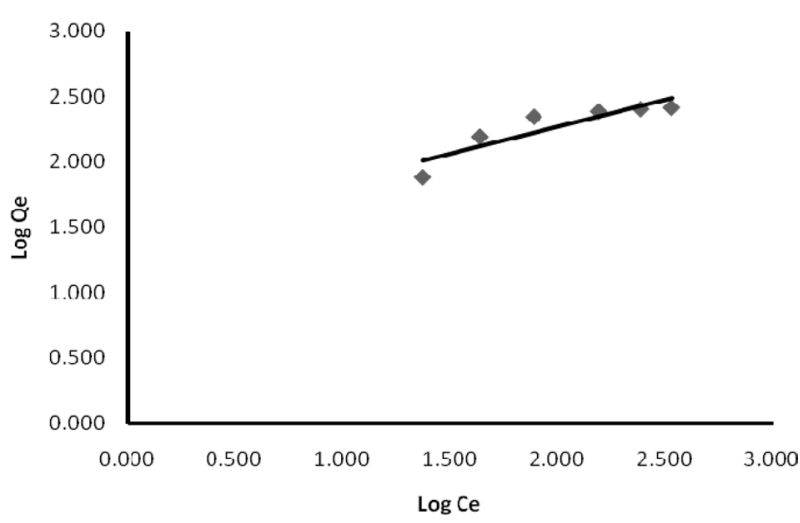

Fig. 10. Freundlich isotherm (temperature $=25^{\circ} \mathrm{C}$, dose $=0.1 \mathrm{~g} / 100 \mathrm{~mL}$, $\mathrm{rpm}=150 \pm 10, \mathrm{pH}=7.8$, equilibrium time $=90 \mathrm{~min}$ ).

\subsection{Adsorption isotherms}

The adsorption data are usually described and modeled using standard adsorption isotherms. They relate the amount of dye adsorbed per unit weight of the adsorbent to the equilibrium concentration of the bulk phase. Fig. 8 presents the adsorption isotherms, which are similar to a type I adsorption isotherm. This indicates that the adsorbent pore size was approximately equal to the molecule size of the adsorbate.
Table 2. Langmuir and Freundlich constants for methylene blue

using lemon grass waste ash

\begin{tabular}{cccc}
\multicolumn{2}{l}{ Langmuir constants } & \multicolumn{2}{l}{ Freundlich constants } \\
\hline $\mathrm{Q}$ & 413.2231 & $\mathrm{~K}_{\mathrm{F}}$ & 27.816 \\
$\mathrm{~b}$ & 0.010754 & $\mathrm{~N}$ & 2.41633442 \\
$\mathrm{R}$ & 0.94477 & $\mathrm{R}$ & 0.89266 \\
$\mathrm{SD}$ & 0.00132 & $\mathrm{SD}$ & 0.10473 \\
$\mathrm{R}_{\mathrm{L}}$ & 0.134184 & - & - \\
\hline
\end{tabular}

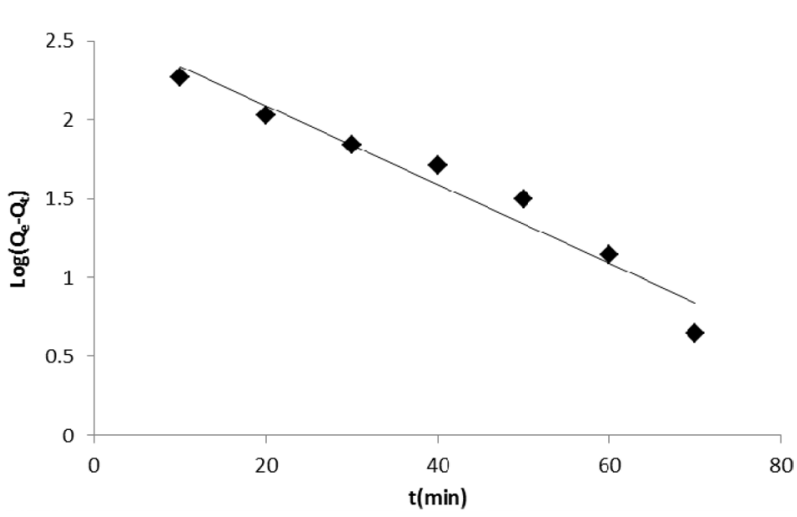

Fig. 11. Pseudo first order plot of contact time on adsorption of methylene blue on lemon grass waste ash.

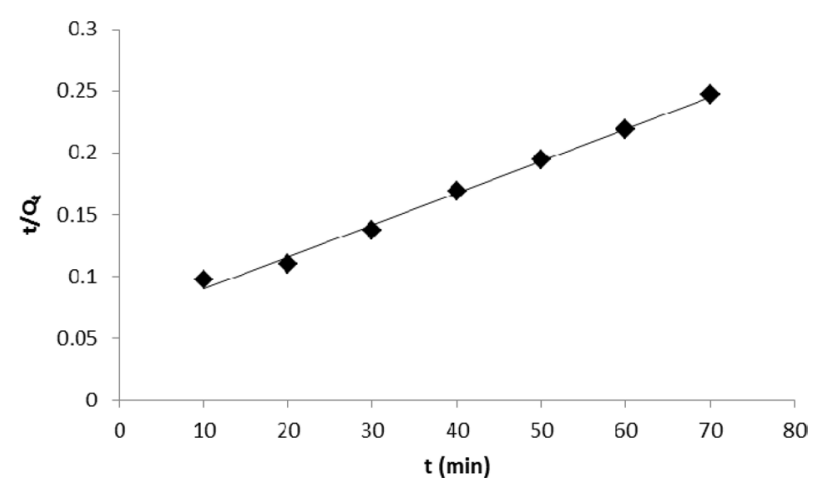

Fig. 12. Pseudo second order plot of contact time on adsorption of methylene blue on lemon grass waste ash.

Experimental data for batch adsorption studies were applied to the Langmuir (Fig. 9) and Freundlich models (Fig. 10). The results obtained from the Langmuir and Freundlich isotherms indicated strong adsorption capacity of lemon grass ash for methylene blue. Adsorption constants for the Langmuir ( $b$ and $\mathrm{Q})$ and Freundlich isotherms $\left(\mathrm{K}_{\mathrm{F}}\right.$ and $\left.\mathrm{n}\right)$ were calculated from the slope and intercept and are given in Table 2. The data fitted the Langmuir isotherm better than the Freundlich isotherm, as indicated by the ' $R$ ' values in Table 2 . A special parameter ' $R_{L}$ ' was also calculated and its value for methylene blue was found to be 0.134 ; the value is between 0 and 1 , and thus indicates that 
Table 3. Constants for Lagergren pseudo-first order and pseudo-second order adsorption kinetic model

\begin{tabular}{ccccccccc}
\multirow{2}{*}{ Adsorbent } & \multicolumn{3}{c}{ Pseudo-first order kinetic model } & \multicolumn{5}{c}{ Pseudo-second order kinetic model } \\
\cline { 2 - 9 } & $\mathrm{Qe}(\mathrm{mg} / \mathrm{g})$ & $\mathrm{k}_{1, \mathrm{ads}}\left(\mathrm{min}^{-1}\right)$ & $\mathrm{R}^{2}$ & $\mathrm{Qe}(\mathrm{mg} / \mathrm{g})$ & $\mathrm{h}(\mathrm{mg} / \mathrm{h} \mathrm{min})$ & $\mathrm{k}_{2}(\mathrm{~g} / \mathrm{mg} \min )$ & $\mathrm{R}^{2}$ \\
\hline Lemon grass ash & 385.878 & 0.057 & 0.952 & 387.597 & 15.579 & 0.0001 & 0.994 \\
\hline
\end{tabular}

the adsorption process was favorable.

Values of Langmuir adsorption capacities (Q) were compared with the values already reported for methylene blue obtained using various low cost materials [19] and it was found that LGA has either comparable or better adsorption capacities than many previously reported low cost materials.

\subsection{Adsorption kinetics}

Adsorption data obtained from the variation in contact time were fitted to the Lagergren pseudo-first order and pseudosecond order adsorption kinetic models and the results are presented in Figs. 11 and 12. Correlation coefficients $\left(\mathrm{R}^{2}\right)$ for the Lagergren pseudo-first order and pseudo-second order kinetic plots were found to be 0.952 and 0.994 , respectively. From these linear plots, values of $\mathrm{Q}_{\mathrm{e}}$ and rate constants were calculated and are presented in Table 3. From the values of $\mathrm{R}^{2}$, it is clear that the pseudo second order model fits better than the first order kinetic model.

\section{Conclusions}

In this study, the "removal of color from wastewater using a low cost adsorbent" was performed by using lemon grass ash. The results of the study reveal that the adsorption process using LGA is a very effective process for the decolorization of methylene blue from wastewater, and it was observed that within 90 min LGA removed $50 \%$ of methylene blue relative to the initial concentration. The results also indicated that the adsorption process was also enhanced by varying the parameters. The parameters used to investigate the adsorption process were adsorbent dose, contact time of adsorbent with dye solution, initial dye concentration on adsorbent, and $\mathrm{pH}$. The test results for these parameters revealed that lemon grass ash strongly influences the adsorption process. The test results are summarized as given below:

1) The results showed that the removal capacity of the adsorbent to remove dye increased with an increase of its dose.

2) The effect of contact time between the adsorbent and the adsorbate showed that with greater duration of contact, the removal of dye from the solution was increased. Equilibrium was achieved at $80 \mathrm{~min}$

3) The amount of dye adsorption increases with an increase in the concentration and the percentage removal decreases exponentially with an increase in the concentration.

4) The result of $\mathrm{pH}$ study shows that the adsorption process is effective at higher $\mathrm{pH}$.

5) Langmuir and Freundlich isotherm parameters $\left(\mathrm{R}^{2} \approx 0.94\right.$, $\mathrm{n}>2, \mathrm{R}_{\mathrm{L}}=0.1348$ ) confirmed that the adsorption of methylene blue on LGA was favorable.
6) Adsorption kinetics of Lagergen pseudo second order model was found to be best fitting kinetic models.

Therefore, the use of lemon grass ash as an adsorbent for the removal of methylene blue from aqueous solutions is recommended as it is not only economical but also an effective alternative to conventional methods.

\section{References}

[1] Chen YM, Tsao TM, Wang MK. Removal of crystal violet and methylene blue from aqueous solution using soil. International Conference on Environment Science and Engineering, Bali Island, Indonesia, 252 (2011).

[2] Shrivastava PV, Hambarde M, Kumar H. Decolorization of textile waste water using low cost adsorbent. Int J Green Herbal Chem, 1, 46 (2012).

[3] Patil S, Renukdas S, Patel N. Removal of methylene blue, a basic dye from aqueous solutions by adsorption using teak tree (Tectona grandis) bark powder. Int J Environ Sci, 1, 711 (2011).

[4] Tsang DW, Hu J, Liu M, Zhang W, Lai KK, Lo IC. Activated carbon produced from waste wood pallets: adsorption of three classes of dyes. Water Air Soil Pollut, 184, 141 (2007). http://dx.doi. org/10.1007/s11270-007-9404-2.

[5] Low L, Teng T, Alkarkhi AM, Ahmad A, Morad N. Optimization of the adsorption conditions for the decolorization and COD reduction of methylene blue aqueous solution using low-cost adsorbent. Water Air Soil Pollut, 214, 185 (2011). http://dx.doi.org/10.1007/ s11270-010-0414-0.

[6] Saha P. Assessment on the removal of methylene blue dye using tamarind fruit shell as biosorbent. Water Air Soil Pollut, 213, 287 (2010). http://dx.doi.org/10.1007/s11270-010-0384-2.

[7] McKay G, Porter JF, Prasad GR. The removal of dye colours from aqueous solutions by adsorption on low-cost materials. Water Air Soil Pollut, 114, 423 (1999). http://dx.doi. org/10.1023/A:1005197308228.

[8] Hu C, Li J, Zhou Y, Li M, Xue F, Li H. Enhanced removal of methylene blue from aqueous solution by pummelo peel pretreated with sodium hydroxide. J Health Sci, 55, 619 (2009). http://dx.doi. org/10.1248/jhs.55.619.

[9] Elass K, Laachach A, Alaoui A, Azzi M. Removal of methylene blue from aqueous solution using ghassoul, a low-cost adsorbent. Appl Ecol Environ Res, 8, 153 (2010).

[10] Santhi T, Manonmani S. Removal of methylene blue from aqueous solution by bio adsorption onto Ricinus communis epicarp activated carbon. Chem Eng Res Bull, 13, 1 (2009). http://dx.doi. org/10.3329/cerb.v13i1.2518.

[11] Rahman MA, Amin SMR, Alam AMS. Removal of methylene blue from waste water using activated carbon prepared from rice husk. Dhaka Univ J Sci, 60, 185 (2012). http://dx.doi.org/10.3329/dujs. v60i2.11491. 
[12] Reddy BS, Ramana KV, Ravindhranath K. Extraction of methylene blue dye from polluted waters using some bioadsorbents. Int J Appl Biol PharmTechnol, 3, 215 (2012).

[13] Velmurugan P, Kumar VR, Dhinakaran G. Dye removal from aqueous solution using low cost adsorbent. Int J Environ Sci, 1, 1492 (2011).

[14] Soni M, Sharma AK, Srivastava JK, Yadav JS. Adsorptive removal of methylene blue dye from an aqueous solution using water hyacinth root powder as a low cost adsorbent. Int J Chem Sci Appl, 3 , 338 (2012).

[15] Elmorsi TM. Equilibrium isotherms and kinetic studies of removal of methylene blue dye by adsorption onto miswak leaves as a natural adsorbent. J Environ Protect, 2, 817 (2011). http://dx.doi. org/10.4236/jep.2011.26093.

[16] Khan TA, Ali I, Vati Singh V, Sharma S. Utilization of fly ash as low-cost adsorbent for the removal of methylene blue, malachite green and rhodamine B dyes from textile wastewater. J Environ Protect Sci, 3, 11 (2009).

[17] Mane RS, Bhusari VN. Removal of colour (dyes) from textile effluent by adsorption using orange and banana peel. Int J Eng Res Appl, 2, 1997 (2012).

[18] Kumar S, Gunasekar V, Ponnusami V. Removal of methylene blue from aqueous effluent using fixed bed of groundnut shell powder. J Chem, 2013, 259819 (2013). http://dx.doi. org/10.1155/2013/259819.

[19] Singh H, Samiksha, Roohi S. Removal of basic dyes from aque- ous solutions using mustard waste ash and buffalo dung ash Int J Environ Sci, 3, 1711 (2013). http://dx.doi.org/10.6088/ ijes.2013030500039.

[20] Srinivasa Rao P, Suresh Reddy KVN, Kalyani S, Krishnaiah A. Comparative sorption of copper and nickel from aqueous solutions by natural neem (Azadirachta indica) sawdust and acid treated sawdust. Wood Sci Technol, 41, 427 (2007). http://dx.doi.org/10.1007/ s00226-006-0115-4.

[21] Namasivayam C, Radhika R, Suba S. Uptake of dyes by a promising locally available agricultural solid waste: coir pith. Waste Manage (Oxford), 21, 381 (2001). http://dx.doi.org/10.1016/S0956053X(00)00081-7.

[22] Babu BV, Gupta S. Adsorption of $\mathrm{Cr}(\mathrm{VI})$ using activated neem leaves: kinetic studies. Adsorption, 14, 85 (2008). http://dx.doi. org/10.1007/s10450-007-9057-X.

[23] Wang XS, Zhou Y, Jiang Y, Sun C. The removal of basic dyes from aqueous solutions using agricultural by-products. J Hazard Mater, 157, 374 (2008). http://dx.doi.org/10.1016/j.jhazmat.2008.01.004.

[24] Malik PK. Use of activated carbons prepared from sawdust and rice-husk for adsorption of acid dyes: a case study of Acid Yellow 36. Dyes Pigments, 56, 239 (2003). http://dx.doi.org/10.1016/ S0143-7208(02)00159-6.

[25] Filipović-Kovačević Z, Sipos L, Briški F. Biosorption of chromium, copper, nickel and zinc ions onto fungal pellet of Aspergillus niger 405 from aqueous solution. Food Technol Biotechnol, 38, $211(2000)$. 